\title{
New Strategies for Caries Prevention. The Role of Alkali Production in Dental Biofilms
}

\author{
Dimitrios Dionysopoulos PhD \\ Department of Operative Dentistry \\ Aristotle University of Thessaloniki \\ Greece
}

\begin{abstract}
Alkali generation by oral bacteria affects the ecology of dental biofilms and the chemical equilibrium between enamel and dentin minerals by neutralizing the acids produced from carbohydrate metabolism on dental plaque. As a matter of fact, it has been postulated that oral alkali production may be a major endogenous caries-inhibiting factor. Conservative dentistry and minimal invasive therapy belong to the most recent trends in management of dental caries. It has been recognized that new approaches to intervene earlier in the caries process using new technologies should be the most appropriate therapy especially in "high caries risk' children and adults. The protective principle of oral alkali production by the action of oral bacteria was found its application to dental practice via oral care products such as toothpastes containing arginine. However, there is insufficient clinical evidence regarding the caries-preventive effect for the inclusion of arginine in toothpastes. Further clinical studies which will not be dependent on commercial interests are necessary to confirm their effectiveness.
\end{abstract}

\section{Editorial}

The introduction of fluoride in dental practice and oral hygiene led to a dramatic decline in caries prevalence worldwide [1]. The mechanism of fluoride anticariogenic action concerns the influence of demineralization and remineralization processes of incipient caries lesions in enamel and dentin [2]. The initial carious lesions should be exposed to sufficient fluoride concentration in the aqueous phase for a prolonged period of time to achieve the anticariogenic effect [3]. In particular, when fluoride ions present in low, sustained concentrations in the oral fluids during an acidic challenge, inhibition of demineralization may occur. Additionally, when the $\mathrm{pH}$ is re-established, low amounts of fluoride ions in oral fluids will make them highly supersaturated with respect to fluorhydroxyapatite, speeding up the remineralization of tooth tissues. The mineral formed under the nucleating action of the partially dissolved minerals will then preferentially include fluoride and exclude carbonate, rendering the enamel more resistant to future acidic challenges [1].

It is well known that dental biofilms, which are the microbial communities that naturally colonize the surfaces of the teeth, exist in a dynamic equilibrium with host defenses and are compatible with the integrity of the dental tissues [4]. A strong correlation has been confirmed between the compositional and metabolic alterations of the dental biofilms and the transition from oral health to pathological conditions such as dental caries [5]. More specifically, it has been reported that frequent acidification of dental biofilms enhances the emergence of an acidogenic and aciduric microflora. This microflora contains the most cariogenic bacteria such as Streptococcus mutans and Lactobacillus species, which ferment dietary carbohydrates rapidly and as a result reduce $\mathrm{pH}$ and enhance demineralization of dental tissues [4]. It has been demonstrated that dental biofilms of caries-free individuals present higher $\mathrm{pH}$ values and elevated ammonia $\left(\mathrm{NH}_{3}\right)$ levels, compared to dental biofilms of caries-active individuals [6].

Alkali generation by oral bacteria affects the ecology of dental biofilms and the chemical equilibrium between enamel and dentin minerals by neutralizing the acids produced from carbohydrate metabolism on dental plaque [7]. As a matter of fact, it has been postulated that oral alkali production may be a major endogenous caries-inhibiting factor [8]. The two main metabolic ways which lead to alkali generation in dental biofilms are the hydrolysis of urea by urease enzymes and the metabolism 
of arginine via the arginine deiminase system (ADS) $[4,6,8]$ Urea is present in salivary secretions and gingival exudates at concentrations around 3-10 mmol/L [9]. Bacterial enzymes (ureases) rapidly break down urea to $\mathrm{NH}_{3}$ and carbon dioxide $\left(\mathrm{CO}_{2}\right)$. Those enzymes are secreted by some species of oral bacteria such as Streptococcus salivarius, Actinomyces naeslundii and oral haemophili [4]. Arginine is an amino-acid and is abundant in salivary secretions (around $50 \mu \mathrm{mol} / \mathrm{L}$ ) [10]. Arginine in the oral cavity is catabolized primarily by the ADS and produce ornithine, $\mathrm{NH}_{3}$ and $\mathrm{CO}_{2}$, providing adenosine tri-phosphate (ATP) [8]. Arginolytic bacteria are abundant in the normal oral flora and include Streptococcus sanguinis, Streptococcus gordonii, Streptococcus parasanguis and Streptococcus mitis, Lactobacillus and Actinomyces species, other oral streptococci and some oral spirochetes $[8,11]$.

Conservative dentistry and minimal invasive therapy belong to the most recent trends in management of dental caries [12]. It has been recognized that new approaches to intervene earlier in the caries process using new technologies should be the most appropriate therapy especially in "high caries risk" children and adults $[12,13]$. The protective principle of oral alkali production by the action of oral bacteria was found its application to dental practice via oral care products such as toothpastes containing arginine [14]. A recently introduced new dentifrice technology based upon $1.5 \%$ arginine and insoluble calcium compound to reduce dental biofilm pathogenicity and enhance remineralization of dental tissues, in combination with fluoride, has been clinically validated. This clinical validation includes a series of clinical studies which assessed the efficacy in arresting and reversing initial enamel and dentin caries lesions [12,14,15-17]. Taking into consideration that fluoride has limitations under pathogenic conditions, because it does not target dental biofilms as its primary mode of action, this toothpaste formulation may be ideally complement the effects of fluoride while targeting dental biofilm pathogenicity.

In most of those clinical studies superior caries benefits have been reported after the use of the arginine-containing dentifrices compared to dentifrices containing fluoride alone. However, there are some questionable research ethics. In particular, in several of the studies the control group used nonfluoride toothpaste. Moreover, due to the existence of conflicts of interest no conclusions can be drawn from studies on the effects of this kind of toothpastes. In addition, arginine-containing toothpastes cost about $40 \%$ more than ordinary fluoride toothpaste. As a result, to determine whether it is more cost-effective, the higher cost must be considered in relation to any additional cariespreventive effect [18].

In conclusion, theoretically the use of arginine-containing dentifrices may be a useful treatment for prevention of dental caries, especially in children and adults. However, there is insufficient clinical evidence regarding the caries-preventive effect for the inclusion of arginine in toothpastes. Further clinical studies which will not be dependent on commercial interests are necessary to confirm their effectiveness.

\section{References}

[1] Buzalaf M.A., Passan J.P., Honorio H.M., ten Cate J.M., Mechanisms of action of fluoride for caries control, Monogr. Oral. Sci. 22, 97-114 (2011).

[2] Dionysopoulos D, Koliniotou-Koumpia E, Helvatzoglou-Antoniades M, Kotsanos N. In vitro inhibition of enamel demineralization by fluoride-releasing restorative materials and dental adhesives. Oral Health Prev Dent, 2016 doi:10.3290/j.ohpd .a35747.

[3] Dionysopoulos D., The effect of fluoride-releasing restorative materials on inhibition of secondary caries formation, Fluoride. 47, 258-265 (2014).

[4] Liu, Y.L., Nascimento, M.M. and Burne, R.A., Progress toward understanding the contribution of alkali generation in dental biofilms to inhibition of dental caries, Int. J. Oral. Sci. 4, 135-140 (2012).

[5] van Houte J., Lopman J., Kent R., The predominant cultivable flora of sound and carious human root surfaces, J. Dent. Res. 73, 1727-1734 (1994).

[6] Margolis H.C., Duckworth J.H., Moreno E.C., Composition of pooled resting plaque fluid from caries-free and caries-susceptible individuals. J. Dent. Res. 67, 1468-1475 (1988).

[7] Dawes C., Dibdin G.H., Salivary concentrations of urea released from a chewing gum containing urea and how these affect the urea content of gel-stabilized plaques and their $\mathrm{pH}$ after exposure to sucrose, Caries. Res. 35, 344-353 (2001). 
[8] Burne R.A., Marquis R.E., Alkali production by oral bacteria and protection a gainst dental caries, FEMS. Microbiol. Lett. 193, 1-6 (2000).

[9] Morou-Bermudez E., Burne R.A., Analysis of urease expression in Actinomyces naeslundii WVU45, Infect. Immun. 68, 6670-6676 (2000).

[10] van Wuyckhuyse B.C., Perinpanayagam H.E., Bevacqua D., Raubertas R.F., Billings R.J., Bowen W.H., Tabak L.A., Association of free arginine and lysine concentrations in human parotid saliva with caries experience, J. Dent. Res. 74, 686-690 (1995).

[11] Liu Y., Nascimento M.M., Schulte R., et al., Characterization of the arginolytic microflora of human dental biofilms, J. Dent. Res. 91, 1262 (2012).

[12] Cummins D., The development and validation of a new technology, based upon $1.5 \%$ arginine, an insoluble calcium compound and fluoride, for everyday use in the prevention and treatment of dental caries, J. Dent. 41, 1-11 (2013).

[13] Frenken J.E., Peters M.C., Manton D.J., Leal S.C., Gordan V.V., Eden E., Minimal intervention dentistry for managing dental caries - a review: report of a FDI task force. Int. Dent. J. 62, 223-243 (2012).

[14] Kraivaphan P., Amornchat C., Triratana T. et al., Two-year caries clinical study of the efficacy of novel dentifrices containing 1.5\% Arginine, an insoluble calcium compound and 1,450 ppm fluoride, Caries. Res. 47, 582-590 (2013).

[15] Yin W., Hua D.Y., Li X., Fan X., Zhang Y.P., Pretty I.A., Mateo L.R., Cummins D., Ellwood R.P., The anti-caries efficacy of a dentifrice containing $1.5 \%$ arginine and 1450 ppm fluoride as sodium monofluorophosphate assessed using Quantitative Light-induced Fluorescence (QLF), J. Dent. 41, 22-28 (2013).

[16] Srisilapanan P., Korwanich N., Yin W., Chuensuwonkul C., Mateo L.R., Zhang Y.P., Cummins D., Ellwood R.P., Comparison of the efficacy of a dentifrice containing $1.5 \%$ arginine and $1450 \mathrm{ppm}$ fluoride to a dentifrice containing $1450 \mathrm{ppm}$ fluoride alone in the management of early coronal caries as assessed using Quantitative Light-induced Fluorescence, J. Dent. 41, 29-34 (2013).

[17] Souza M.L.R., Cury J.A., Tenuta L.M.A., Zhang Y.P., Mateo L.R., Cummins D., Ellwood R.P., Comparing the efficacy of a dentifrice containing $1.5 \%$ arginine and $1450 \mathrm{ppm}$ fluoride to a dentifrice containing $1450 \mathrm{ppm}$ fluoride alone in the management of primary root caries, J. Dent. 41, 35-41 (2013).

[18] Ástvaldsdóttir Á, Naimi-Akbar A, Davidson T, Brolund A, Lintamo L, Attergren Granath A, Tranæus S, Östlund P. Arginine and Caries Prevention: A Systematic Review, Caries. Res. 50, 383-393 (2016). 